Michael Stürner

Europäisches Vertragsrecht 


\section{lus Communitatis}

Herausgegeben von

Prof. Dr. Dr. Stefan Grundmann, LL.M. (Berkeley) 


\section{Michael Stürner}

\section{Europäisches \\ Vertragsrecht}

Institutionelle und methodische Grundlagen, materielles Recht, Kollisionsrecht 
Prof. Dr. Michael Stürner, M.Jur. (Oxford), Lehrstuhl für Bürgerliches Recht, Internationales Privatrecht und Rechtsvergleichung an der Universität Konstanz sowie Richter am Oberlandesgericht Karlsruhe.

ISBN 978-3-11-071823-2

e-ISBN (PDF) 978-3-11-071869-0

e-ISBN (EPUB) 978-3-11-071874-4

Library of Congress Control Number: 2020948130

Bibliografische Information der Deutschen Nationalbibliothek

Die Deutsche Nationalbibliothek verzeichnet diese Publikation in der Deutschen Nationalbibliografie; detaillierte bibliografische Daten sind im Internet über http://dnb.dnb.de abrufbar.

(C) 2021 Walter de Gruyter GmbH, Berlin/Boston

Einbandabbildung: akg-images: „Bauhaustreppe“, 1932, Oskar Schlemmer

Satz: jürgen ullrich typosatz, Nördlingen

Druck und Bindung: CPI books $\mathrm{GmbH}$, Leck

www.degruyter.com 
Für Juliane, Delia und Greta 
